\title{
Deep current structure in the Toyama Deep-Sea Channel in the Japan Sea
}

\author{
Tomoharu Senjyu ${ }^{1}[0$
}

Received: 14 June 2021 / Revised: 18 September 2021 / Accepted: 22 October 2021 / Published online: 29 October 2021

This is a U.S. government work and not under copyright protection in the U.S.; foreign copyright protection may apply 2021

\begin{abstract}
The flow field in the Toyama Deep-Sea Channel (TDSC) in the Japan Sea was investigated based on mooring observations. An asymmetric current system accompanying offshore and onshore currents over the east- and west-side slopes in the channel, respectively, is suggested. A bottom intensified flow characteristic was observed at the offshore stations in the Yamato Basin. The asymmetric current system in the channel is also suggested by the asymmetric distribution of water characteristics across the TDSC in Toyama Bay; a cold dense water mass with higher dissolved oxygen (DO) and higher transmittance (Tr) was found over the west-side slope of the channel, whereas a water mass with lower DO and lower Tr was distributed over the east-side slope, suggesting a turbidity current from the head of Toyama Bay. The currents facing the shallower depth on their right-hand-side, along with the density distribution in the TDSC, suggest a density current system under the influence of the earth's rotation. The dissolved oxygen concentration in the TDSC was significantly lower than that in the offshore region of the same temperature range. This suggests that the water mass over the west-side slope in the TDSC is a modified offshore water mass which experienced significant mixing with the low DO water mass over the east-side slope in the TDSC, probably due to strong shear between the offshore and onshore currents in the narrow channel.
\end{abstract}

Keywords Toyama Bay · Toyama Trough · Toyama Deep-Sea Channel · Japan Sea · Mooring observations · Asymmetric current system · Earth's rotation effect · Turbidity currents · Land-deep sea material transport, · Deep currents

\section{Introduction}

Toyama Bay is one of the deepest bays in Japan that is characterized by a deep trough called the Toyama Trough (Fig. 1b). At the head of the Toyama Bay, there are many canyons incised into the floor of the shelf margin that are known as a good fishing ground called "Fuke" or "Aigame" by local fishermen. Several deep-sea fish species such as oarfish (Regalecus russelii) and giant squid (Architeuthis sp.) have occasionally been beached or caught in coastal fisheries set-nets in the bay head (Hirasawa and Nambu 2016; Kimura et al. 2020, 2021). This suggests that the trough and canyons are a means for the deep-sea fishes to approach the coastal area. In fact, many fisheries set-nets in the coastal area are set taking into account the location and direction

Tomoharu Senjyu

senjyu@riam.kyushu-u.ac.jp

1 Research Institute for Applied Mechanics, Kyushu University, 6-1 Kasuga-koen, Kasuga City, Fukuoka 816-8580, Japan of the canyons (Okei et al. 2008). The Toyama Trough is the southern part of the Toyama Deep-Sea Channel (TDSC) that extends approximately $750 \mathrm{~km}$ from the Toyama Bay to the east of the Yamato Rise in the Japan Basin across the Yamato Basin (Fig. 1a). The bottom depth in the TDSC varies from less than $1000 \mathrm{~m}$ in Toyama Bay to $3500 \mathrm{~m}$ in the Japan Basin via 1200-2300 $\mathrm{m}$ in the Toyama Trough and 2300-3000 $\mathrm{m}$ in the Yamato Basin (Nakajima et al. 1998).

Material transport from land to deep sea through the TDSC has been suggested from the turbidite distributions and the sediment core samples obtained in and around the TDSC (Nakajima et al. 1998). In fact, terrigenous sediment depositions have been detected from the deep-sea fan at the end of the TDSC in the Japan Basin (Okamura et al. 2002; Nakajima 2006). This suggests the existence of an offshore current directed away from the Toyama Bay toward the deep ocean in the TDSC. The occurrence of small-scale turbidity currents triggered by a seasonal flood is suggested, although the mean recurrent period of the large-scale turbidity currents reaching the terminal zone of the TDSC is estimated to be approximately 70 years during the last millennium 

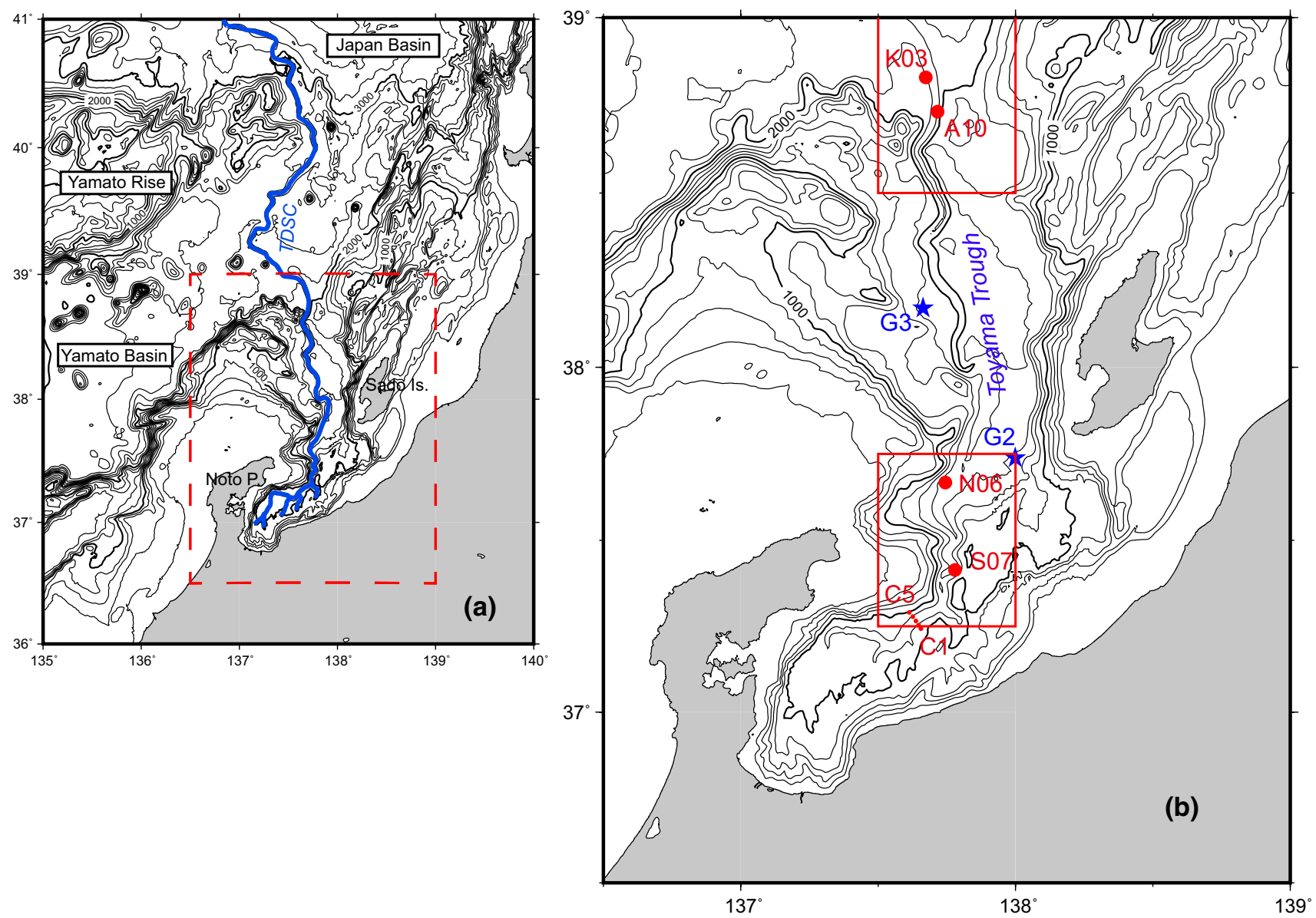

Fig. 1 Bottom topography around the Toyama Deep-Sea Channel (TDSC) and the observation stations. The blue meandering curve in a indicates the TDSC. The enlarged map of the area surrounded by a red broken line in $\mathbf{a}$ is shown in $\mathbf{b}$. The red circles labeled K03, A10, N06, and S07 in b show the mooring sites of the current meters. The red dots indicate the hydrographic stations across the channel (Stas. $\mathrm{C} 1-\mathrm{C} 5$ in Fig. 9). The blue stars labeled G2 and G3 are hydrographic stations by the JMA. The areas delineated by the orange rectangles in b are shown in Fig. 8 (color figure online)

TDSC, as well as a hydrographic observation once. The deep current system in the TDSC is discussed by compiling our datasets with those of the previously reported currents. The next section introduces our observations along with the previously reported datasets. In Sect. 3, a general description of the currents in the TDSC is provided. The deep current system in the TDSC is discussed in Sect. 4 based on the current and hydrographic datasets. Finally, our concluding remarks are provided in Sect. 5.

\section{Observations and data}

The mooring observations of deep currents in the TSDC were conducted during the periods 2006-2007, 2007-2008, and 2010-2011 (Fig. 1b and Table 1). In the first observations at Sta. N06, the RCM8 type current meters manufactured by Aanderaa Instruments were 
Table 1 Location, water depth, instrument depth, duration, and instrument type at each observation site

\begin{tabular}{lllllll}
\hline Sta & Lat $(\mathrm{N})$ & Long $(\mathrm{E})$ & W. depth $(\mathrm{m})$ & Inst. depth $(\mathrm{m})$ & Duration & Inst. type \\
\hline N06 & $37^{\circ} 40.0^{\prime}$ & $137^{\circ} 44.7^{\prime}$ & 1650 & 710 & 23 Aug. 2006-14 Aug. 2007 & RCM8 \\
& & & & 935 & 23 Aug. 2006-14 Aug. 2007 & RCM8 \\
& & & & 1300 & 23 Aug. 2006-14 Aug. 2007 & RCM8 \\
S07 & $37^{\circ} 24.8^{\prime}$ & $137^{\circ} 46.8^{\prime}$ & 1475 & 900 & 14 Aug. 2007-13 Aug. 2008 & RCM8 \\
& & & & 1380 & 14 Aug. 2007-13 Aug. 2008 & RCM8 \\
A10 & $38^{\circ} 44.0^{\prime}$ & $137^{\circ} 43.0^{\prime}$ & 2249 & 1000 & 12 Oct. 2010-3 Oct. 2011 & Seaguard \\
& & & & 1540 & 12 Oct. 2010-3 Oct. 2011 & Aquadopp \\
& & & & 2000 & 12 Oct. 2010-3 Oct. 2011 & Seaguard \\
K03 & $38^{\circ} 49.8^{\prime}$ & $137^{\circ} 40.4^{\prime}$ & 2204 & 2104 & 6 Jul. 2003-2 Sep. 2004 & RCM11 \\
& & & & 2154 & 6 Jul. 2003-2 Sep. 2004 & RCM11 \\
\hline
\end{tabular}

deployed at depths of 710, 935, and $1300 \mathrm{~m}$ during August 2006-August 2007 (Fig. 2b). A similar mooring line with two current meters at 900 and $1380 \mathrm{~m}$ was subsequently deployed at Sta. S07 during August 2007-August 2008 (Fig. 2a). Both mooring stations are located in the Toyama Trough between Noto Peninsula and Sado Island where the water depth is approximately $1500 \mathrm{~m}$ (Fig. 1b). The third mooring observations were performed at Sta. A10, an offshore region further in the Yamato Basin where the water depth is greater than $2000 \mathrm{~m}$, during October 2010-October 2011. In the observations at Sta. A10, acoustic singlepoint Doppler current meters (Seaguard instruments with a Z-Pulse sensor manufactured by Aanderaa Instruments and a DW-Aquadopp by Nortek Inc.) were deployed at 1000 , 1540, and $2000 \mathrm{~m}$ (Fig. 2c). The measurement interval in the first and second observations was set at $1 \mathrm{~h}$, whereas that in the third observation was set at $30 \mathrm{~min}$. All the

(a)

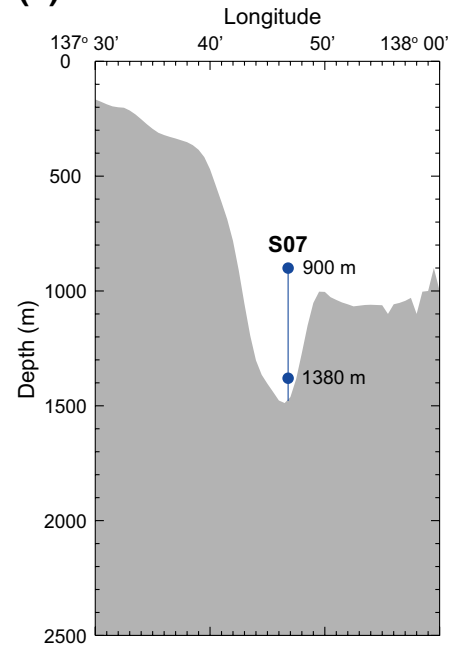

(b)

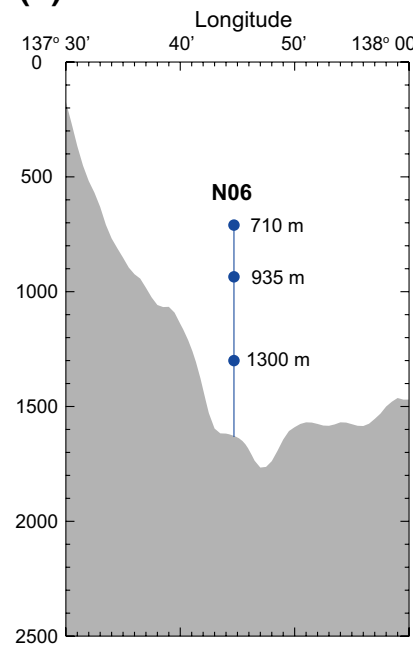

deployment and recovering of the mooring lines were conducted by T/V Nagasaki Maru of Nagasaki University.

In addition to our observational datasets, the current data measured by the Japan Coast Guard at Sta. K03 in the TDSC in the Yamato Basin are analyzed (Fig. $1 \mathrm{~b}$ and Table 1). In these observations, two acoustic current meters (RCM11, Aanderaa Instruments) were deployed at 2104 and $2154 \mathrm{~m}$ (Fig. 2d) during the period July 2003-September 2004 with a measurement interval of $1 \mathrm{~h}$ (Fukushima and Kojima 2011).

As the RCM8 type current meter measures flow speeds with a mechanical rotor, its response to a weak flow is slow and the nominal starting velocity is $2.0 \mathrm{~cm} \mathrm{~s}^{-1}$, although its accuracy of flow speed is nominally $\pm 1.0 \mathrm{~cm} \mathrm{~s}^{-1}$. By contrast, RCM11, Seaguard, and Aquadopp current meters which determine flow speeds by measuring the Doppler shift of back-scattered supersonic sound signal provide superior performance with the (c)

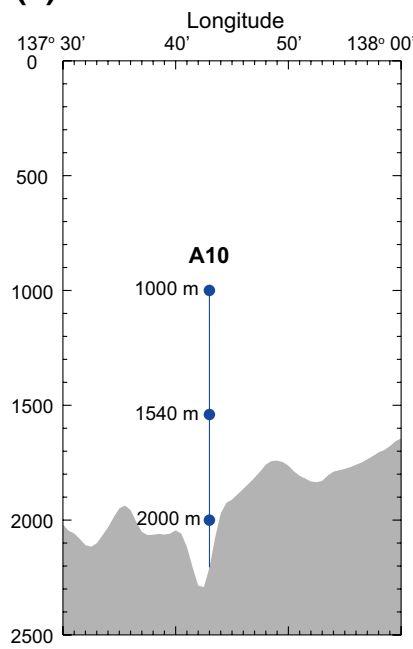

(d)

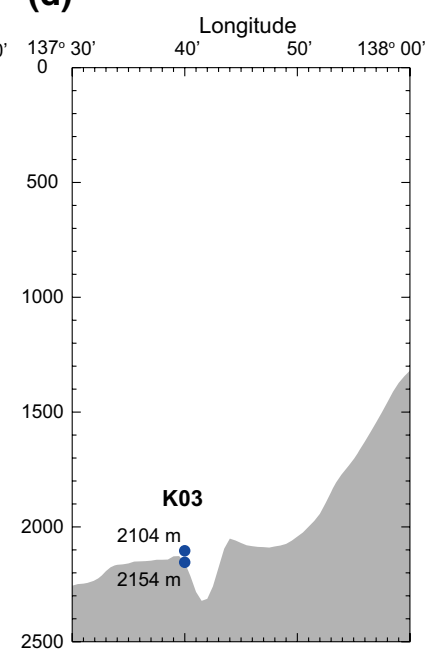

Fig. 2 Sectional distributions of current meters (blue circles connected by a blue line) and bottom topography across the channel (shaded area): a Sta. S07, b N06, c A10, and d K03. The bottom topography along a latitude line nearby each station is drawn based on the JTOPO30 (color figure online) 
nominal accuracies of $\pm 0.15, \pm 0.15$, and $\pm 0.5 \mathrm{~cm} \mathrm{~s}^{-1}$, respectively, without starting velocity. A comparison of performance between RCM8 and RCM11 was reported in Nakano et al. (2008).

Hydrographic observations across the Toyama Trough in Toyama Bay were conducted at Stas. C1-C5 on 15 November 2020 using a conductivity-temperature-depth profiler (CTD; SBE911plus, Sea-Bird Scientific) with a dissolved oxygen (DO) sensor (SBE43, Sea-Bird Scientific) and a transmittance (Tr) sensor (C-Star transmissometer, Sea-Bird Scientific) (Fig. 1). The transmissometer measures beam transmittance in the $25 \mathrm{~cm}$ path length using a light of $410 \mathrm{~nm}$ of wavelength. Therefore, lower $\operatorname{Tr}$ water indicates more turbid water.

As a reference of the water mass around the TDSC, the hydrographic observation data obtained at Stas. G2 and G3 in an offshore region were analyzed (Fig. 1b). These observations were conducted by the Japan Meteorological Agency (JMA) on 7 November 2020, 8 days before our observations, as Stas. KS5901 and KS5900, respectively.

The bathymetry in this study relies on the JTOPO30 version 2 provided from the Marine Information Research Center (MIRC), Japan Hydrographic Association, which provides the gridded bottom topography with $30 \mathrm{~s}$ (approximately $1 \mathrm{~km}$ ) spatial resolution in both latitude and longitude. According to the MIRC, the bottom topography in this study area was derived from the high precision multi-beam sounding data (http://www.mirc.jha.jp/ products/JTOPO30v2/).

\section{Results}

As our specific interest was in the low frequency currents, the general features of the currents in the TDSC are described based on the low-pass filtered current data using a 48-h tide killer filter (Hanawa and Mitsudera 1985). The stick diagrams shown in this section are drawn using the daily subsampled current data. Since currents in the TDSC are strongly influenced by the bottom topography, we defined the two orthogonal principal axes: the major principal axis in the direction which the standard deviations are maximal in a hodograph (Kundu and Allen 1976) and the minor principal axis perpendicular to the major principal one (Table 2). The mean and standard deviation for the observed currents were evaluated for the major $(V)$ and minor $(U)$ principal axis components, as well as the vector mean.

The currents at Sta. A10 exhibited dominant north to northeastward currents throughout the year, particularly at 1540 and $2000 \mathrm{~m}$ (Fig. 3), which is consistent with the offshore material transport in the TDSC suggested by Nakajima et al. (1998). The currents exhibited a bottomintensified characteristic; the vector-mean current speed at

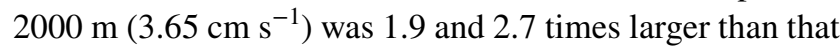
at $1540\left(1.89 \mathrm{~cm} \mathrm{~s}^{-1}\right)$ and $1000 \mathrm{~m}\left(1.34 \mathrm{~cm} \mathrm{~s}^{-1}\right)$, respectively (Table 2). This bottom-intensified characteristic was also reflected in the large values of the direction stability that is defined by the ratio of the vector mean speed to the scaler mean speed, although standard deviation of the major principal axis component $\left(V_{s d}\right)$ increased with depth. Accordingly, the eddy kinetic energy $\left(K_{e}\right)$ also increased with depth; however, the ratio of $K_{e}$ to the mean kinetic energy $\left(K_{m}\right)$ at $2000 \mathrm{~m}$ showed the lowest value among the three layers.

Table 2 Basic statistics of the currents at each observation site. Directions of the mean current and the major principal axis are measured clockwise from the north

\begin{tabular}{|c|c|c|c|c|c|c|c|c|c|c|c|c|}
\hline \multirow[t]{2}{*}{ Station } & \multirow[t]{2}{*}{ Inst depth (m) } & \multirow{2}{*}{$\begin{array}{l}\text { Major prin- } \\
\text { cipal axis } \\
\left({ }^{\circ} \mathrm{T}\right)\end{array}$} & \multicolumn{4}{|l|}{ Mean } & \multicolumn{2}{|c|}{$\begin{array}{l}\text { Standard devia- } \\
\text { tion }\end{array}$} & \multirow[t]{2}{*}{$\begin{array}{l}\text { Direction } \\
\text { stability }\end{array}$} & \multicolumn{3}{|c|}{ Kinetic Energy } \\
\hline & & & $\begin{array}{l}\text { Direction } \\
\left({ }^{\circ} \mathrm{T}\right)\end{array}$ & $\begin{array}{l}\text { Speed } \\
\left(\mathrm{cms}^{-1}\right)\end{array}$ & $\begin{array}{l}\bar{V} \\
\left(\mathrm{cms}^{-1}\right)\end{array}$ & $\begin{array}{l}\bar{U} \\
\left(\mathrm{cms}^{-1}\right)\end{array}$ & $\begin{array}{l}V_{s d} \\
\left(\mathrm{cms}^{-1}\right)\end{array}$ & $\begin{array}{l}U_{s d} \\
\left(\mathrm{cms}^{-1}\right)\end{array}$ & & $\begin{array}{l}K_{m} \\
\left(\mathrm{~cm}^{2} \mathrm{~s}^{-2}\right)\end{array}$ & $\begin{array}{l}K_{e} \\
\left(\mathrm{~cm}^{2} \mathrm{~s}^{-2}\right)\end{array}$ & $K_{e} / K_{m}$ \\
\hline \multirow[t]{3}{*}{ N06 } & 710 & 0.9 & 204.2 & 0.93 & -0.85 & -0.37 & 2.81 & 2.04 & 0.63 & 0.43 & 6.02 & 14.0 \\
\hline & 935 & 28.7 & 206.5 & 1.07 & -1.06 & 0.04 & 1.86 & 0.86 & 0.75 & 0.57 & 2.10 & 3.7 \\
\hline & 1300 & 39.0 & 216.3 & 0.97 & -0.97 & 0.05 & 1.91 & 0.77 & 0.76 & 0.47 & 2.12 & 4.5 \\
\hline \multirow[t]{2}{*}{ S07 } & 900 & 41.0 & 43.9 & 0.65 & 0.65 & 0.03 & 1.97 & 0.72 & 0.46 & 0.21 & 2.19 & 10.5 \\
\hline & 1380 & 16.8 & 147.8 & 0.47 & -0.30 & 0.35 & 1.79 & 0.80 & 0.35 & 0.11 & 1.93 & 17.9 \\
\hline \multirow[t]{3}{*}{ A10 } & 1000 & 26.1 & 55.0 & 1.34 & 1.18 & 0.65 & 1.88 & 1.22 & 0.60 & 0.90 & 2.51 & 2.8 \\
\hline & 1540 & 30.7 & 41.2 & 1.89 & 1.85 & 0.34 & 1.93 & 1.25 & 0.76 & 1.78 & 2.65 & 1.5 \\
\hline & 2000 & 23.2 & 25.3 & 3.65 & 3.64 & 0.13 & 2.91 & 1.15 & 0.88 & 6.64 & 4.90 & 0.7 \\
\hline \multirow[t]{2}{*}{ K03 } & 2104 & 178.2 & 168.3 & 2.59 & 2.55 & -0.45 & 1.92 & 2.29 & 0.75 & 3.34 & 4.47 & 1.3 \\
\hline & 2154 & 170.7 & 167.5 & 3.11 & 3.11 & -0.18 & 2.07 & 2.45 & 0.80 & 4.84 & 5.14 & 1.3 \\
\hline
\end{tabular}




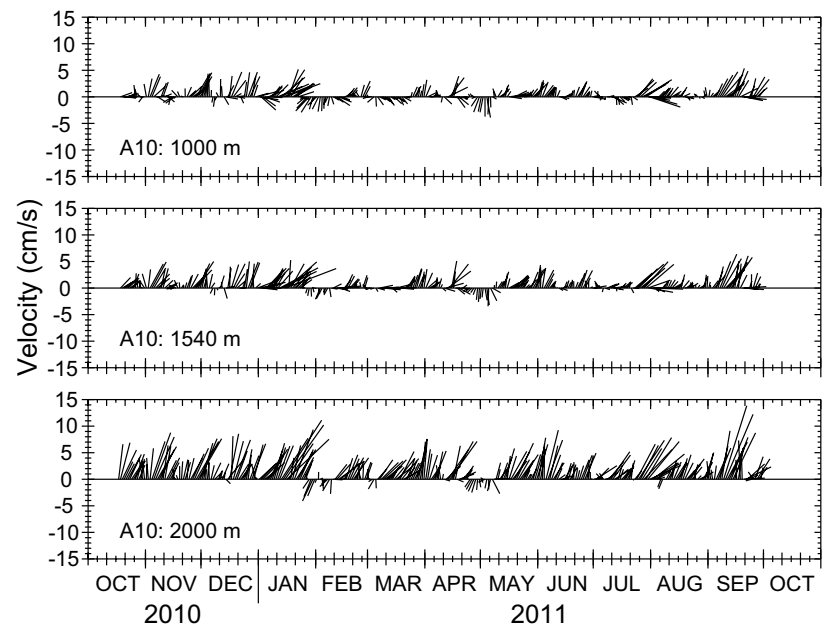

Fig. 3 Time series of current vectors at 1000, 1540, and $2000 \mathrm{~m}$ at Sta. A10. The sticks showing the current vector were subsampled every $24 \mathrm{~h}$. Upward and rightward sticks indicate northward and eastward currents, respectively
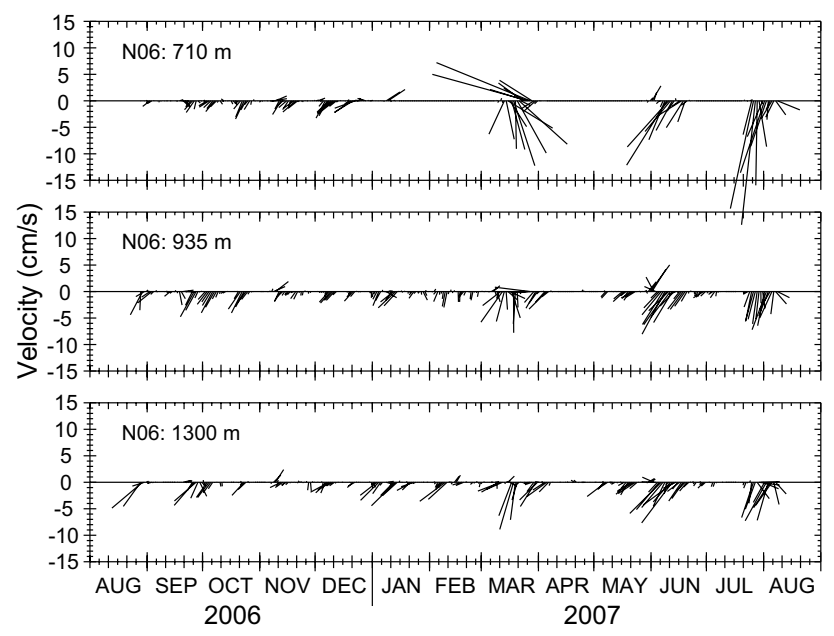

Fig. 4 Time series of current vectors at 710, 935, and $1300 \mathrm{~m}$ at Sta. N06. Upward and rightward sticks indicate northward and eastward currents, respectively

In contrast, the currents at Sta. N06 were directed southwestward which corresponds to the onshore water movement toward Toyama Bay (Fig. 4). A notable intermittent characteristic of the currents was observed, although part of the intermittency may be due to the less sensitivity to weak flows of the RCM8 type current meters. Three strong current events exceeding $8 \mathrm{~cm} \mathrm{~s}^{-1}$ occurred in March, June, and late July in 2007 at all the layers, following the moderate current period of approximately $5 \mathrm{~cm} \mathrm{~s}^{-1}$ from August 2006 to February 2007. The large flow amplitude at $710 \mathrm{~m}$ during the events suggests an influence of the upper layer flow condition. In fact, the satellite infrared images indicated a meandering of the Tsushima Current (Fig. 5b) and an intrusion of warm water around the mooring site (Fig. 5c) during the second and third events, respectively, although remarkable oceanic features were indiscernible during the first event (Fig. 5a). Correspondingly, the largest $K_{e}$ was found at $710 \mathrm{~m}$, although the direction and speed of the mean currents for the observation period were almost the same between the three layers (Table 2).

Similar onshore deep currents were observed at Sta. K03 throughout the observation period at both 2104 and $2154 \mathrm{~m}$, as described by Fukushima and Kojima (2011) (Fig. 6). However, unlike the currents at Sta. N06, the flows at Sta. K03 fluctuated zonally with approximately a 2-month periodicity, which is reflected in the larger standard deviation of the minor principal axis component $\left(U_{s d}\right)$ than $V_{s d}$ (Table 2). The vector mean current speeds indicated a slight bottom intensification similar to Sta. A10, although the mean current directions were almost opposite between Stas. K03 and A10.

Sta. S07 showed bidirectional currents toward the northeast or south that occurred alternatively at an interval of approximately 20 days at both 900 and $1380 \mathrm{~m}$ (Fig. 7), which were reflected in the low direction stabilities (Table 2). Although the mean current direction at $900 \mathrm{~m}$ $\left(43.9^{\circ}\right)$ coincided with the direction of major principal axis $\left(41.0^{\circ}\right)$, that at $1380 \mathrm{~m}\left(147.8^{\circ}\right)$ was nearly perpendicular to the major principal axis $\left(16.8^{\circ}\right)$ because of the stronger southward flows than that at $900 \mathrm{~m}$. The level of $K_{e}$ at Sta. S07 was comparable to that at similar depths at other stations (i.e., 935 and $1300 \mathrm{~m}$ at Sta. N06 and 1000 and $1540 \mathrm{~m}$ at Sta. A10); however, the values of $K_{e} / K_{m}$ were greater than 10 because of the small $K_{m}$.

Although the top and intermediate current meters at Stas. N06 and A10 were positioned far from the seabed where topographic constrains are absent (Fig. 2b and 2c), the mean current at the levels showed a similar direction to that at the bottom current meter along the channel (Fig. 8), suggesting a topographic influence throughout the depths. The vertically coherent flow structure (quasi-barotropic characteristic) has been reported commonly in the abyssal Japan Sea (Takematsu et al. 1999; Senjyu et al. 2005). However, the topographic influence seems to weaken with distance from the bottom; the mean currents at Sta. A10 rotated clockwise upward and the major principal axis at the top current meter at Sta. N06 was deviated from the channel direction.

\section{Discussion}

The mean currents at each station are directed either offshore or onshore in several directions (Fig. 8). Notably, the mean currents of almost opposite directions appeared at Stas. A10 and K03 which are approximately only $10 \mathrm{~km}$ 

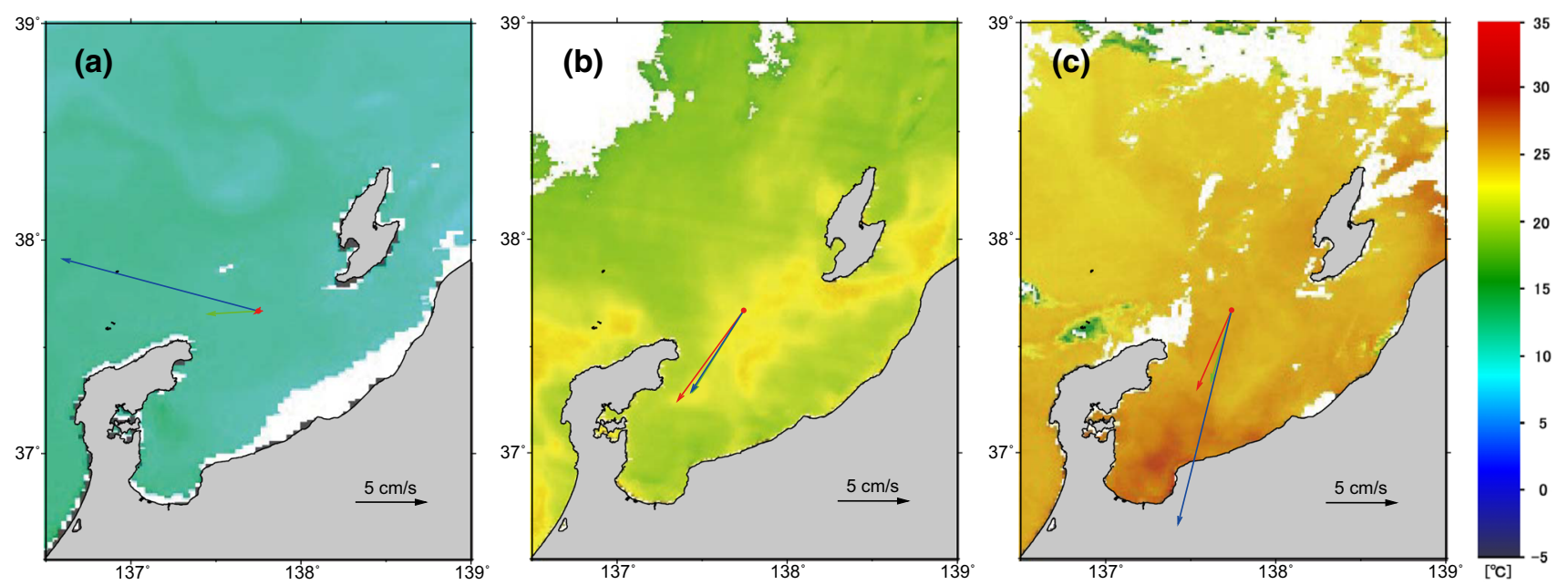

Fig. 5 Satellite infrared images obtained by the moderate resolution imaging spectroradiometer (MODIS) sensor on the Terra or Aqua satellites during the strong current events: a 04:37 on 26 March 2007, b $01: 35$ on 12 June 2007, and c $04: 18$ on 27 June 2007. Red circle and arrows indicate the location of Sta. N06 and the current vectors at 710 (blue), 935 (green), and $1300 \mathrm{~m}$ (red) at the corresponding time, respectively (color figure online)

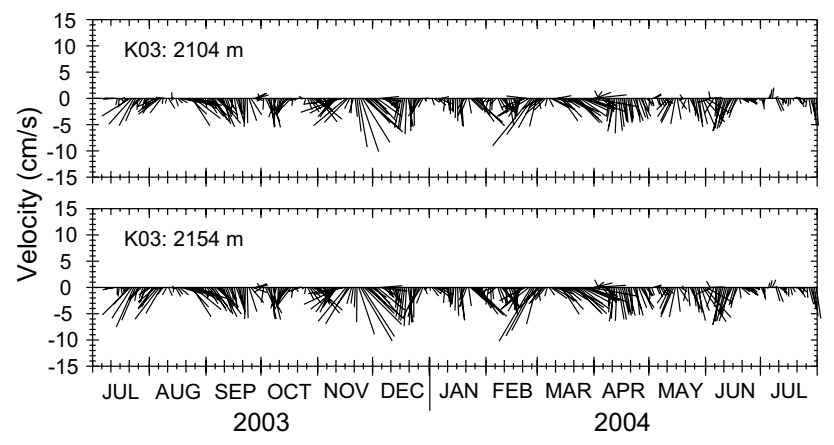

Fig. 6 Time series of current vectors at 2104 and $2154 \mathrm{~m}$ at Sta. K03. Upward and rightward sticks indicate northward and eastward currents, respectively

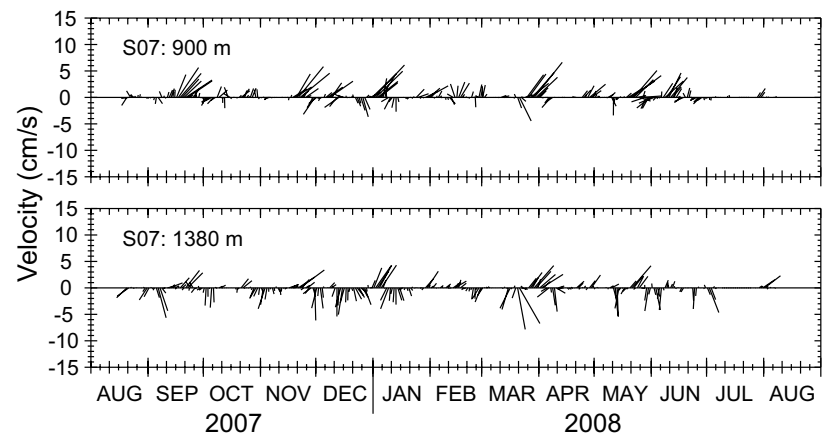

Fig. 7 Time series of current vectors at 900 and $1380 \mathrm{~m}$ at Sta. S07. Upward and rightward sticks indicate northward and eastward currents, respectively apart across the channel (Fig. 8a). If we take into account the location of the ravine in the channel, a common feature of the mean currents is revealed. Stas. K03 and N06 showing onshore mean currents are located on the west-side of the ravine. In contrast, Sta. A10 showing the offshore mean currents is located on the east-side slope in the channel. In summary, the mean flow at a station is in the direction facing the shallower depth on their right-hand-side. The bidirectional flows at Sta. S07 are ascribed to the fact that the mooring site was located on the bottom of the channel (ravine) rather than on the slope (Fig. 2a). Flows over the ravine are likely to be susceptible to fluctuations in deep currents over both east- and west-side slopes. A similar asymmetric current system with opposite currents facing shallower depths on their right-hand-side in the channel has been reported from the Izu-Ogasawara Trench southeast of Japan (Fujio et al. 2000), although the geographical scale of the TDSC is much smaller than that of the trench.

The opposing currents in the TDSC are also suggested by the sectional distributions of water characteristics across the channel. DO and Tr clearly depicted asymmetric distributions across the channel below approximately $800 \mathrm{~m}$ (Fig. 9c and d, the location of the section is shown in Fig. 1). Over the west-side slope in the channel, a water mass of higher DO and higher Tr than that over the eastside slope was distributed. The contours of $0.3{ }^{\circ} \mathrm{C}$ and $27.34 \sigma_{\theta}$ indicated that this water mass is colder and denser than that over the east-side slope at the same depth level (Fig. 9a and b). At Sta. C3 over the ravine of the channel, the water mass of higher DO and higher Tr from the 
Fig. 8 Distributions of the mean current vectors for a Stas. A10 and K03 and b Stas. N06 and S07 (the areas are shown in Fig. 1b). The red, green, and blue arrows indicate the mean current vectors at the bottom, middle, and top observation layers at each station, respectively (Table 2). The ellipses plotted at the tip of the mean current vectors specify the standard deviations of the fluctuating components in the direction of major and minor principal axes. The scale of $1.0 \mathrm{~cm} \mathrm{~s}^{-1}$ is shown in the upper-right corner of each panel. The red broken line indicates the ravine of the TDSC (color figure online) (a)

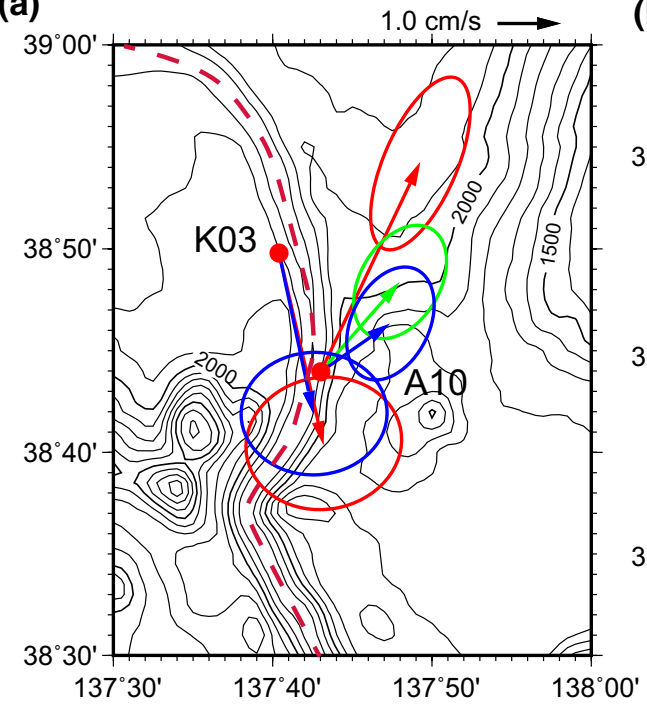

(b)

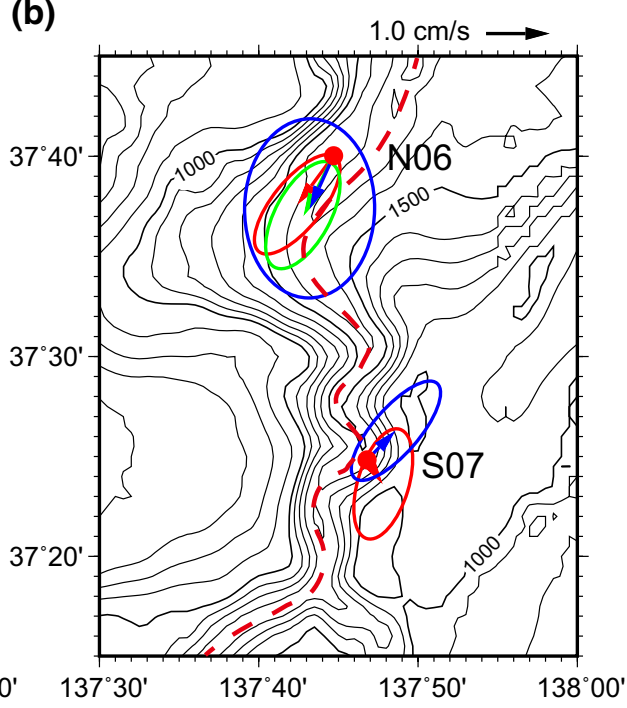

west-side slope underlies the lower DO and lower Tr water mass from the east-side slope. Such flow and density distributions in the channel suggest a density current system under the influence of the earth's rotation (Griffiths 1986).

Considering the mass and vorticity conservations, the onshore current over the west-side slope should be returned to offshore along an isobath on the east-side slope in the channel, unless the water mass obtains buoyancy. Therefore, the water mass of higher DO and higher Tr on the west-side slope was likely to be advected horizontally by the onshore current over the west-side slope at the depth level. In contrast, the lower DO and lower Tr (turbid) water mass over the east-side slope appears to be intruded from the head of Toyama Bay along the eastern flank of the channel under the influence of the Coriolis force. The cause of the low Tr in the water mass is unknown; however, if the low $\operatorname{Tr}$ was owing to suspension of materials such as mud and silt, the water mass could hold a negative buoyancy and flow down the channel toward the bay mouth as a turbidity current (Simpson 1997). The low DO concentration in the water mass is possibly due to the active oxygen consumption in the high turbidity water (Sato 1979; Senjyu et al. 2001).

The water masses at Stas. G2 and G3 in the offshore area were compared with those over the east-side (Stas. C1 and $\mathrm{C} 2$ ) and west-side (Stas. C4 and C5) slopes in the TDSC (Fig. 1). The $\theta-$ DO diagram reveals that the DO concentration in the TDSC was significantly lower than that in the offshore region in the range of $\theta<0.7{ }^{\circ} \mathrm{C}$ (Fig. 10). The water mass over the west-side slope lies between that on the east-side slope and the offshore water mass below the range of $\theta<0.4{ }^{\circ} \mathrm{C}$, where the east-west contrast in $\operatorname{Tr}$ was clear (Fig. 9). This suggests that the water on the west-side slope is the modified offshore water mass which underwent significant mixing with the low DO water on the east-side slope in the TDSC, probably due to strong shear between the offshore and onshore currents in the narrow channel.

The turbidity currents on the east-side slope anticipate a bottom-intensified offshore flow over the east-side slope. At Sta. A10, the offshore currents exhibited the bottom-intensified characteristic, whereas the onshore currents were almost the same amplitude throughout the observation depths (Fig. 3). In fact, the mean speeds of the offshore current along the major principal axis increased with depth (1.95, 2.37 , and $4.23 \mathrm{~cm} \mathrm{~s}^{-1}$ at 1000,1540 , and $2000 \mathrm{~m}$, respectively). In contrast, those for the onshore currents showed no significant difference among the depths $(-1.08,-0.91$, and $-1.58 \mathrm{~cm} \mathrm{~s}^{-1}$ at 1000,1540 , and $2000 \mathrm{~m}$ ). This suggests the existence of turbidity currents at Sta. A10 in the offshore region, although the distribution of water properties at this station is unknown. The occurrence of hyperpycnal flow triggered by a seasonal river flood has been suggested in Toyama Bay (Nakajima 2006). The hyperpycnal flows, which are "autosuspended" turbidity currents, occur when the density of flooding river effluent exceeds that of the ambient sea water in the river mouth area and can propagate over a long distance due to its "autosuspended mechanism" with strong turbulence (Wright et al. 1986).

\section{Concluding remarks}

The flow field in the TDSC was investigated based on mooring observations. An asymmetric current system, offshore and onshore currents over the east- and west-side slopes in the channel, respectively, is suggested in the TDSC (Fig. 8). The offshore (onshore) current transports the lower (higher) DO and lower (higher) Tr water mass over the east-side (west-side) slope, suggesting a turbidity current from the 
Fig. 9 Sectional distributions of a potential temperature $(\theta$, unit $\left.{ }^{\circ} \mathrm{C}\right)$, b potential density $\left(\sigma_{\theta}\right), \mathbf{c}$ dissolved oxygen (DO, $\mu \mathrm{mol}$ $\left.\mathrm{kg}^{-1}\right)$, and $\mathbf{d}$ transmittance $(\mathrm{Tr}$, $\%$ ) across the channel (Stas. C1-C5 in Fig. 1b). The bottom topography (shaded area) is based on the ship-mounted echo sounder records at the observations
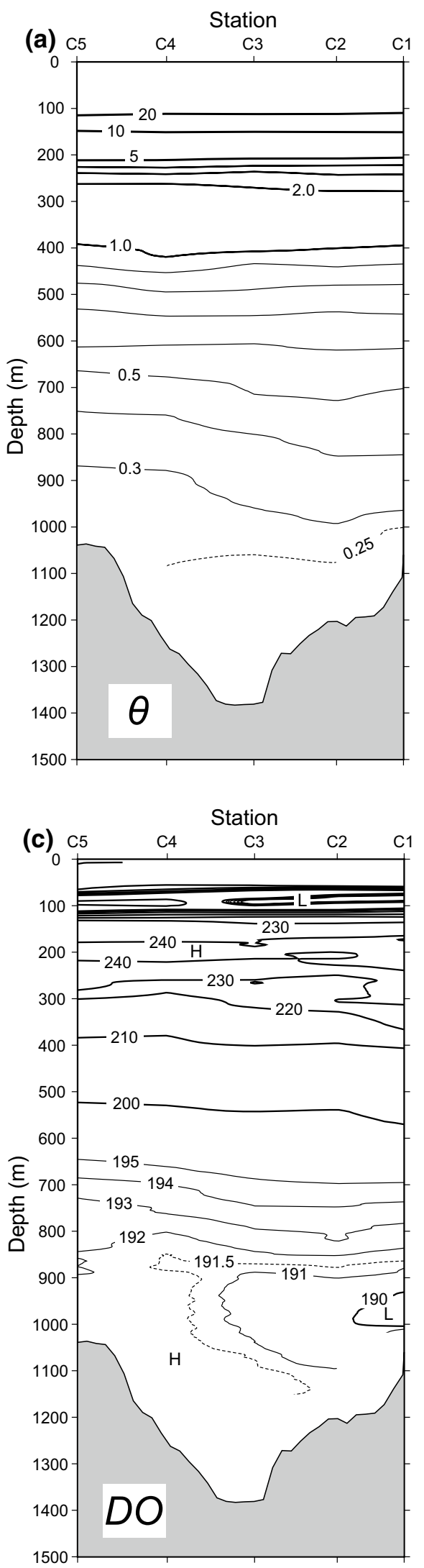
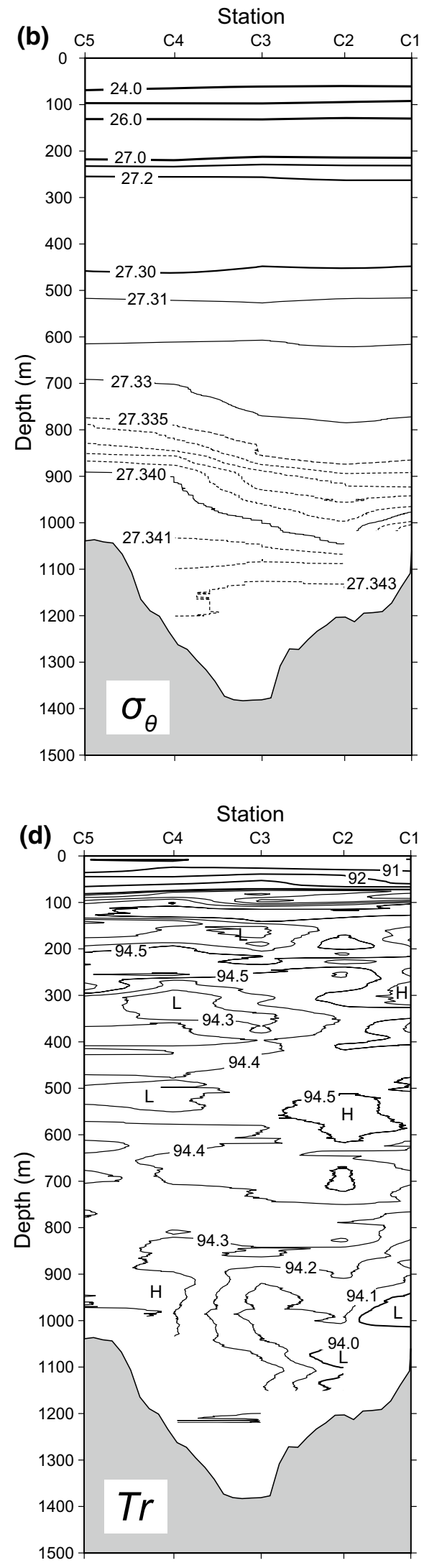


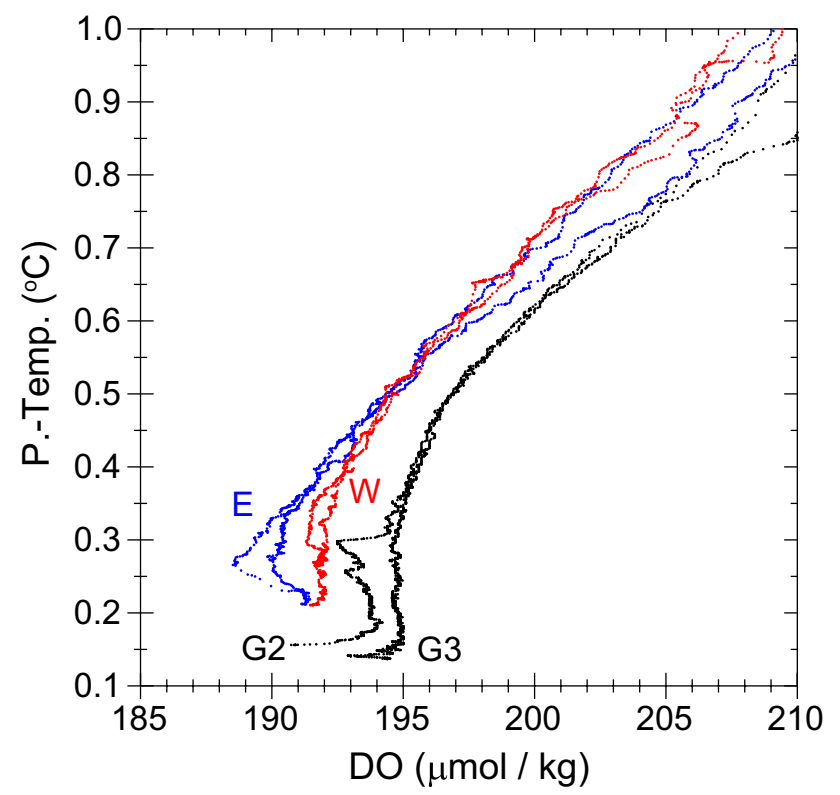

Fig. $10 \theta-\mathrm{DO}$ diagram for Stas. G2 and G3 in the offshore region (black), Stas. C1 and C2 on the east-side slope (blue), and Stas. C4 and C5 over the west-side slope (red) in the TDSC (color figure online)

head of Toyama Bay (Fig. 9). The current and density distributions in the TDSC suggest a density current system controlled by the earth's rotation. The $\theta-\mathrm{DO}$ diagram suggests significant mixing between the lower DO water mass on the east-side slope and the higher DO water mass originating from the offshore region due to horizontal shear between the offshore and onshore currents in the TDSC.

As our results are based on the mooring observations conducted at different periods at the four stations, concurrent mooring observations on the east- and west-side slopes across the channel are essential to confirm the asymmetric current system in the TDSC. In addition, the driving mechanism governing this asymmetric current system could not be clarified, although the possibility of turbidity currents in the TDSC was suggested. Furthermore, the periodical flow fluctuations at Sta. K03, along with the bottom-intensified characteristic (Figs. 6 and 8), suggest the existence of bottom-trapped topographic Rossby waves (TRWs) in the channel (Rhines 1970). Although the dynamics of TRWs in the TDSC is out of scope of this study, the TRWs are probably a key factor controlling current fluctuations in the channel, together with the occurrence of turbidity currents and the meandering of the Tsushima Current in the upper layer. To clarify the source and modification process of water masses and the TRWs propagation in the TDSC, mooring and hydrographic observations along the channel are desired.

If the asymmetric current system in the TDSC is durable and robust, it can influence the material transport between land and deep sea. The asymmetric height of the levees along the TDSC, the east-side levee higher than the westside one (Nakajima et al. 1998), is probably attributable to the asymmetric current system in the channel. Asymmetric features between the east- and west-side slopes may be found in size and composition of the deposited sediments and the habitat of benthic organisms in the channel, in accordance with the asymmetric distribution of water mass.

Acknowledgements We would like to thank the captain and crew of the T/V Nagasaki Maru of Nagasaki University for helping with the field observations. S. Nakada of the National Institute of Environmental Studies is acknowledged for the helpful comments. The original manuscript has been greatly improved by insightful comments from two anonymous reviewers. The current data at Sta. K03 and hydrographic data at Stas. G2 and G3 were downloaded from the web sites of the Japan Oceanographic Data Center and the JMA, respectively. The satellite infrared images were provided by the Japan Aerospace Exploration Agency from https://www.eorc.jaxa.jp/cgi-bin/adeos/modis_index.cgi. This study was partly supported by the JSPS KAKENHI, Grant Numbers JP18H03741 and JP19H04245.

Open Access This article is licensed under a Creative Commons Attribution 4.0 International License, which permits use, sharing, adaptation, distribution and reproduction in any medium or format, as long as you give appropriate credit to the original author(s) and the source, provide a link to the Creative Commons licence, and indicate if changes were made. The images or other third party material in this article are included in the article's Creative Commons licence, unless indicated otherwise in a credit line to the material. If material is not included in the article's Creative Commons licence and your intended use is not permitted by statutory regulation or exceeds the permitted use, you will need to obtain permission directly from the copyright holder. To view a copy of this licence, visit http://creativecommons.org/licenses/by/4.0/.

\section{References}

Fujio S, Yanagimoto D, Taira K (2000) Deep current structure above the Izu-Ogasawara Trench. J Geophys Res 105:6377-6386

Fukushima S, Kojima T (2011) Characteristics of deep current observed near the bottom in the Sea of Japan. Rep Hydrogr Oceanogr Res 47:32-43

Griffiths RW (1986) Gravity currents in rotating systems. Ann Rev Fluid Mech 18:59-89

Hanawa K, Mitsudera H (1985) On the data processing of daily mean values of oceanographical data - note on the daily mean sea-level data. Bull Coastal Oceanogr 23:79-87

Hirasawa S, Nambu H (2016) Giant squid Auchiteuthis sp. discovered from Toyama Bay, Toyama Prefecture (December 2015, January 2016). Bull Toyama Sci Museum 40:127-134

Kimura T, Kusama S, Fuwa M, Inamura O (2020) Record of slender oarfish Regalecus russelii in Toyama Bay, Sea of Japan (until March 2019). Ann Rep Uozu Aquarium 29:38-48

Kimura T, Kusama S, Fuwa M, Inamura O (2021) Record of slender oarfish Regalecus russelii in Toyama Bay, Sea of Japan (fiscal year ending March 2020). Ann Rep Uozu Aquarium 30:34-38

Kundu PK, Allen JS (1976) Some three-dimensional characteristics of low-frequency current fluctuations near the Oregon coast. J Phys Oceanogr 6:181-199 
Nakada S, Hirose N (2009) Seasonal upwelling underneath the Tsushima Warm Current along the Japanese shelf slope. J Mar Syst 78:206-213

Nakajima T (2006) Hyperpycnites deposited $700 \mathrm{~km}$ away from river mouths in the central Japan Sea. J Sediment Res 76:60-73

Nakajima T, Satoh M, Okamura Y (1998) Channel-levee complexes, terminal deep-sea fan and sediment wave fields associated with the Toyama Deep-Sea Channel system in the Japan Sea. Mar Geol 147:25-41

Nakano T, Ishizaki H, Shikama N (2008) Comparison of data from four current meters obtained by long-term deep-sea moorings. Tec Rep MRI 55:1-22

Okei N, Okuno J, Senjyu T (2008) Kyucho observed along the eastern coast of the Noto Peninsula. Kaiyo Mon Extra 47:71-78

Okamura Y, Satake K, Takeuchi A (2002) Detailed geometry of the lowermost part of the Toyama Deep Sea Channel. Rekishi Jishin 18:221-225

Rhines P (1970) Edge-, bottom-, and Rossby waves in a rotating stratified fluid. Geophys Fluid Dyn 1:273-302
Sato Y (1979) A laboratory study on dissolved oxygen-consumption of sea mud. Bull Tokai Reg Fish Res Lab 98:55-64

Senjyu T, Shin HR, Yoon JH, Nagano Z, An HS, Byun SK, Lee CK (2005) Deep flow field in the Japan/East Sea as deduced from direct current measurements. Deep-Sea Res II 52:1726-1741

Senjyu T, Yasuda H, Sugihara S, Kamizono M (2001) Current and turbidity variations in the western part of Suo-nada, the Seto Inland Sea, Japan: a hypothesis on the oxygen-deficient water mass formation. J Oceanogr 57:15-27

Simpson JE (1997) Gravity Currents: in the environment and the laboratory, 2nd edn. Cambridge University Press, Cambridge, p 244

Takematsu M, Nagano Z, Ostrovskii AG, Kim K, Volkov Y (1999) Direct measurements of deep currents in the northern Japan Sea. J Oceanogr 55:207-216. https://doi.org/10.1023/A:1007842013257

Wright LD, Yang ZS, Bornhold BD, Keller GH, Prior DB, Wiseman WJ Jr (1986) Hyperpycnal plumes and plume fronts over the Huanghe (Yellow river) delta front. Geo-Mar Lett 6:97-105 